\title{
Evaluating Alternative Linear Vernier Hybrid Machine Topologies for Integration into Wave Energy Converters
}

\author{
Nick J. Baker, Mohammad A.H. Raihan, Ahmed A. Almoraya, Joseph W. Burchell, Markus A. Mueller
}

\begin{abstract}
This paper discusses the development of linear Vernier Hybrid Machines for use in wave energy converters. A number of topology options are explored to reduce magnet usage and improve performance for use as a linear generator. Consequent pole, $\mathrm{V}$-shape and Halbach arrays are designed for a target $25 \mathrm{~kW}$ specification. A discussion of overall cost of energy produced is used to justify using efficiency and power factor to asses fixed magnet mass topology variants. A power factor improvement from 0.38 to 0.72 is presented.

Physical integration of the electrical machine into wave energy converters is considered including flooded experimental results of thermal behavior and polymer bearing wear.
\end{abstract}

Index Terms - bearing wear, flooded machines, linear generators, vernier hybrid machines, wave energy,

\section{INTRODUCTION}

$\mathrm{W}$ AVE energy converters are likely to require electrical machines optimized for slow speed, reciprocating and possibly linear motion. As such, a number of permanent magnet linear topologies have been investigated for this application [1]. Linear synchronous machines such as [2, 3] can have the magnets and coils mounted on separate components. For linear configurations, however, there is an incentive to have the magnets and coils both mounted within the stator to allow the translator to be a purely iron structure. A number of authors have investigated flux switching [4], transverse flux [5], superconducting [6] and Vernier Hybrid Machines (VHM) [710] for wave devices. More generally, various topologies of the linear VHM have recently been introduced [11-14] and analyzed [15-17]. These topologies all have the reputation of high force per magnet mass, but only when operating with a relatively poor power factor, e.g. [18]. Most works to date have considered force density, and magnet mass, with some consideration of cogging force and power factor. Sections III and IV below agree with the general consensus that by increasing magnet mass, reducing electric loading and other relatively minor topology changes, it is possible to reduce inductance and hence have a lower $\mathrm{kVA}$ rating in the converter - all at the expense of increased machine assembly cost or complexity. There is hence a system level design challenge, not yet addressed elsewhere, on how to get the best machine for a wave energy converter in terms of lifetime cost of energy.

Furthermore, integration of the linear generator into the wave device presents significant challenges due to the harsh marine environment. In conventional electrical machines windings and bearings exhibit some of the highest failure rates [19]. If a conventional generator topology is used, it is installed as a separate component in a sealed environment, rather than being integrated into the actual wave device [20-22]. Full integration into a wave device can be achieved by considering flooded operation, in which seawater is allowed to flood the internal parts of the machine. The bearing design becomes challenging as a sophisticated sealing arrangement is then required if conventional bearings are deployed, which adds to CAPEX, and O\&M costs.

At present there is no off-the-shelf linear bearing system available for flooded operation and so integrated design is not possible without due consideration of the tribology. As well as the requirement for being easily maintainable, the bearings are critical in ensuring the survivability of the complete wave energy system.

As winding life is directly linked to temperature any improvement in cooling represents an improvement in lifetime performance. Flooded operation hence presents an opportunity in terms of improved thermal performance of linear machines, and in survivability.

In this paper a $25 \mathrm{~kW}$ specification is used to compare the performance of a number of machine topologies all belonging to the same family. A discussion of the economic implications of efficiency and power factor is given to provide a method for evaluating designs for this application. For each variant a fixed magnet mass design is optimized first for peak force, and secondly for an improved power factor. Integration of the machines into direct drive wave energy converters is considered by presenting results from lubrication and sealing tests.

\section{SPECIFICATION AND EvAlUATION}

In wave energy, there are uncertainties in terms of resource, device architecture and rated verses average and overload values of power in addition to control algorithms and non-linear effects of mixed seas, making a general design study challenging. To aid with this and allow general machine designs

This work was supported in part by the UK EPSRC under Grant EP/N021452/1.

N. J. Baker, is a Senior Lecturer within Newcastle University's Electrical Power Group. He is a machine designer with research projects across the automotive, aerospace and renewable energy sector; M.A. Raihan and A. A. Almoraya are working towards PhD degrees at Newcastle university in the area of linear machine development; J. Burchell is a research associate within the Institute of Energy Systems, University of Edinburgh; M.A. Mueller is Professor within the Institute of Energy Systems, University of Edinburgh 
to be investigated, the following assumptions are made:

- Deep sinusoidal waves with a significant wave height of $\mathrm{H}_{\mathrm{s}}=2.75 \mathrm{~m}$, simplified to a wave $2.75 \mathrm{~m}$ peak to peak, $(1.375$ $\mathrm{m}$ amplitude) and period 7.25 seconds.

- Device restricted to heave following profile of the wave

- Average power is $50 \%$ of available power

- $25 \mathrm{~kW}$ is average real electrical power output

- Electrical power converter efficiency $=95 \%$

- Rms input to electrical power converter $=26.5 \mathrm{~kW}$

- Generator consists of 10 equal $2.5 \mathrm{~kW}$ modules TABLE I: DESIGN PARAMETERS

\begin{tabular}{|c|c|c|}
\hline Parameter & Value & Unit \\
\hline $\begin{array}{l}\text { Number of } \\
\text { modules }\end{array}$ & 30 & \\
\hline $\begin{array}{l}\text { Average real power } \\
\text { output }\end{array}$ & 25 & $\mathrm{~kW}$ \\
\hline Rated force & 44 & $\mathrm{kN}$ \\
\hline Overload force & 81 & $\mathrm{kN}$ \\
\hline $\begin{array}{l}\text { Amplitude of } \\
\text { oscillation }\end{array}$ & 1.375 & M \\
\hline $\mathrm{V}_{\text {phase }}$ output & 240 & $\mathrm{~V}_{\text {rms }}$ \\
\hline Current Density & 3.5 & $\mathrm{~A} / \mathrm{mm}^{2} \mathrm{rms}$ \\
\hline (rated) & 7 & $\mathrm{~A} / \mathrm{mm}^{2}$ peak \\
\hline Current Density & 12 & $\mathrm{~A} / \mathrm{mm}^{2} \mathrm{rms}$ \\
\hline (overload) & 17 & $\mathrm{~A} / \mathrm{mm}^{2}$ peak \\
\hline airgap & 1 & $\mathrm{~mm}$ \\
\hline
\end{tabular}

Table I shows a specification for a $25 \mathrm{~kW}$ heaving buoy used for this electrical machine design study. Values of current density include a nominal fill factor and are chosen to remove the need for an external cooling circuit. Identical material characteristics assuming standard grade electrical steel (M270 35A) and Neodymium Iron Boron magnets are used in all cases.

Fundamentally, electrical machines are sized on their rated torque or force. For a permanent magnet machine, the design can be altered depending on whether machine size, cost, efficiency, power factor or force ripple is prioritized. In reality, it is a compromise between all these conflicting requirements and geometry is varied until a happy compromise is reached.

Power factor is the ratio of real and reactive power for the generator. A machine with a lower power factor hence requires a larger converter to deliver the same real power. A generator's operating power factor is hence an important variable when assessing the economics of alternative electrical machines. The Carbon Trust argued that for wave energy converters, it is Cost of Energy $(\mathrm{CoE})$ that is most important, based on Present Values $(P V)$ [23]. CoE is a measure of the total cost to build, install, run and decommission a device, divided by the total energy it generates over its lifetime. Using this metric, the cost of energy of the electrical drive will be of the form given in (1).

$$
\begin{aligned}
& C o E=\frac{£}{k W h} \\
& =\frac{\text { capital } \cos t+P V(\text { operation } \& \text { maintenance cost })}{P V(\text { energy produced over device life time })} \\
& =\frac{C A P E X+O P E X}{P_{\text {wave }} \eta} \times \text { constant }
\end{aligned}
$$

Operational expenditure (OPEX) and capital expenditure (CAPEX) are subject to environmental and economic factors beyond the control of the electrical machine designer. However, with four assumptions, it is possible to simplify (1) to a more useful form suitable for design evaluation. Firstly, assuming a fixed wave resource is available for all generator designs fixes the available power $P_{\text {wave }}$. Secondly, OPEX for a brushless generator can be assumed to be small compared to its CAPEX. Thirdly, the CAPEX of a PM machine is assumed to be heavily dependent on the mass of magnet material used. Fourthly, the cost of a power converter is assumed to vary linearly with its $\mathrm{kVA}$ rating. Equation (1) can now be simplified to (2).

$$
C o E \approx \frac{A \times \text { magnet mass }+B \times 1 / \text { power factor }}{\eta}
$$

Where $A$ is the supply and processing cost of magnet material used in the electrical machine $(\$ / \mathrm{kg})$ and $B$ is the market value of a power converter based on its rating $(\$ / \mathrm{kVA})$.

Further, if the magnet mass between designs is fixed, it ceases to be a consideration and the cost of energy can be further summarized as the simple relationship of (3).

$$
C o E=f(\eta, \text { power factor })
$$

This is similar to the arguments presented in [24], where the life cycle cost (equivalent to $C o E$ ) is found to be primarily dependent on machine efficiency and not CAPEX.

Efficiency and power factor are hence provided in the following sections to evaluate alternative machine types. Losses consist of iron loss and copper loss, with the latter dominating. An investigation of topologies which allow a reduction in current density for a fixed force are presented. If resistance is ignored, power factor can be shown to be given by (4) $[25,26]$.

$$
P F=\frac{1}{\sqrt{1+\left(\frac{L_{S} I}{\Psi_{m}}\right)}}
$$

Where $L_{s}$ is the synchronous inductance, $I$ is the phase current in RMS and $\Psi_{m}$ is the magnet flux linkage. Therefore, according to (4) the power factor of these machines can be improved by either reducing the inductance or phase current, or by increasing the flux linkage.

Throughout this paper, the computed efficiencies are based on mechanical output power and copper, iron and magnet losses calculated using 2D FEA.

\section{TOPOLOGY DEVELOPMENT}

\section{A. Baseline Vernier Hybrid Machine}

The Vernier Hybrid Machine (VHM) is a member of the variable reluctance PM machine family and exhibits high force density due to the reluctance variation of the slotted translator modulating the field from the PMs causing flux reversal. Each stator tooth hosts a number of stator poles and a fractional slot winding. The VHM with surface mounted PMs is here used as a baseline machine as it is known for high power and force density with simple and rigid structural construction as shown in Fig.1.

Magnets and windings are both mounted on the stator, while 
the laminated translator with salient teeth is sandwiched between the stator sides. The translator has a simple, rigid rectangular structure making it capable of transmitting the thrust force.

In [7] a VHM was presented where each phase consists of two C-core stators facing each other. A three phase machine therefore consists of six C-cores. The three $\mathrm{C}$-core units on each side can be integrated together to make two 3-phase E-core units that reduce the active volume of the machine, increase the robustness and mechanical stability [27], as shown in Fig 1.

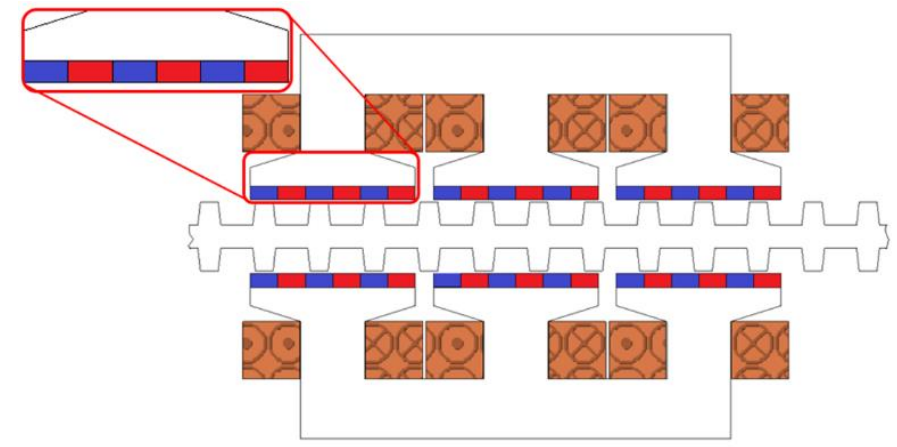

Fig. 1. A single three phase module of the baseline VHM

Each three phase generator module consists of two E-cores that are electrically and magnetically decoupled and can form independent 3-phase units. The advantage of two neighboring E-cores is that, by $180^{\circ}$ electrical phase shift between them, it is possible to reduce the cogging and force ripple and thus improve the performance of the machine [27].

This configuration is here defined as the baseline machine for a design study and the topology has been taken forward to three alternative configurations. The key common parameters for all for machines are listed in Table II.

TABLE II: MACHINE PARAMETERS

\begin{tabular}{lc}
\hline \hline Parameter & value \\
\hline Number of phases & 3 \\
Stator pole pair width $(\mathrm{mm})$ & 24 \\
Translator slot pitch $(\mathrm{mm})$ & 24 \\
Width of Stator tooth shoe $(\mathrm{mm})$ & 72 \\
Stack length (mm) & 50 \\
Machine active length (mm) & 488 \\
Height of the translator teeth $(\mathrm{mm})$ & 10 \\
Airgap (mm) & 1 \\
Number of active translator teeth & 10 \\
Translator thickness $(\mathrm{mm})$ & 30 \\
Magnet remanence, $B_{r}(\mathrm{~T})$ & 1.24 \\
\hline \hline
\end{tabular}

\section{B. The Consequent Pole VHM}

The Consequent Pole (CP) machine possesses the same basic structure and operation principle as the baseline VHM, except that alternate PMs are replaced with tapered ferromagnetic teeth, the consequent poles [28]. All remaining magnets have the same polarity (south), while the ferromagnetic poles operate as north poles as shown in Fig. 2. Hence, the number of PM pole pairs of the baseline VHM and consequent pole machines are equal, yet the number of magnet pieces has halved. For a fixed magnet mass comparison, each individual magnet in the consequent pole machine is double the thickness. In other studies, magnet dimensions have been fixed and using consequent poles was said to reduce the active airgap and thus reluctance, giving a significant improvement of the force and power density [29].

Fig. 3 shows that this topology exhibits smaller pole to pole flux leakage compared to its surface mounted counterpart. In the surface mounted baseline machine, almost no useful flux emanates from the two right-hand magnets. In the CP version, whilst leakage is still prevalent, all magnets are at least contributing to the main flux path.

The effect of employing tapered consequent pole on the back EMF and cogging force characteristics has been investigated in [8]. Reduction of the fringing flux results in an increase in the peak flux linkage, the rate of change of flux linkage and therefore the no-load back EMF. The machine is now doubly salient, which could imply the $\mathrm{CP}$ would benefit from phase advance. In fact, in this topology the salient effect is negligible as the effect of the top and bottom stators cancel each other out.

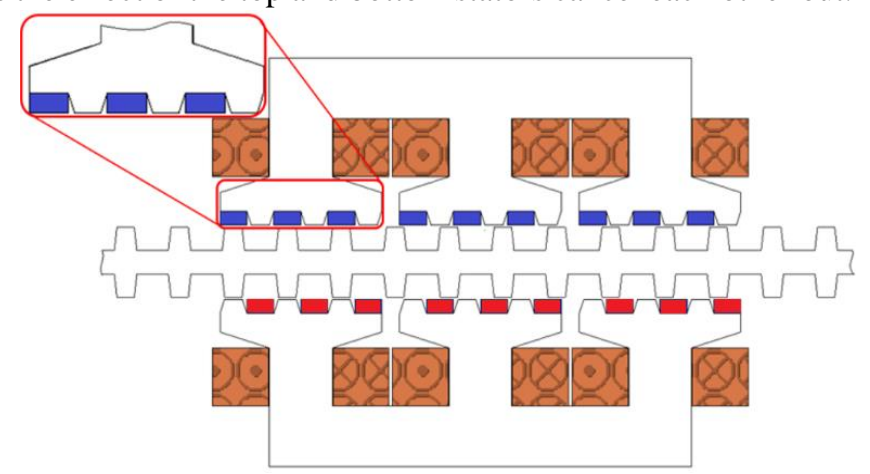

Fig.2. Consequent Pole (CP) topology.
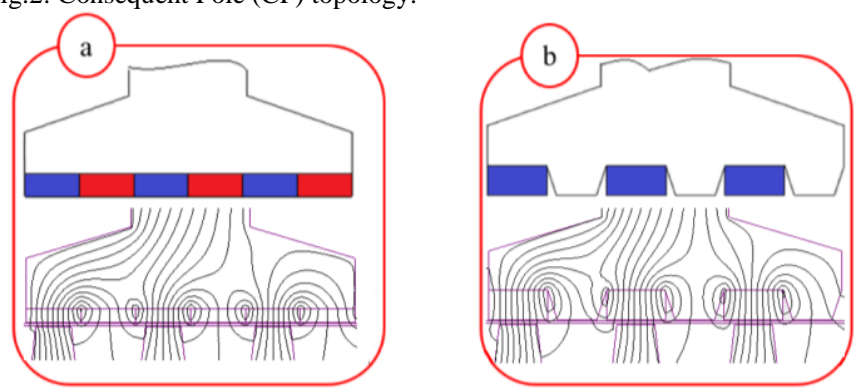

Fig.3. Pole to pole leakage flux (a) baseline (b) consequent pole.

\section{V Shape}

In order to use flux concentration, individual magnet segments of the baseline machine are split into a $\mathrm{V}$ shape configuration, similar to that proposed in more conventional rotary machines [30]. Each pole consists of two identical magnets and a triangular pole piece, which can either be held in place with or without an iron rib, as shown in Fig. 4.

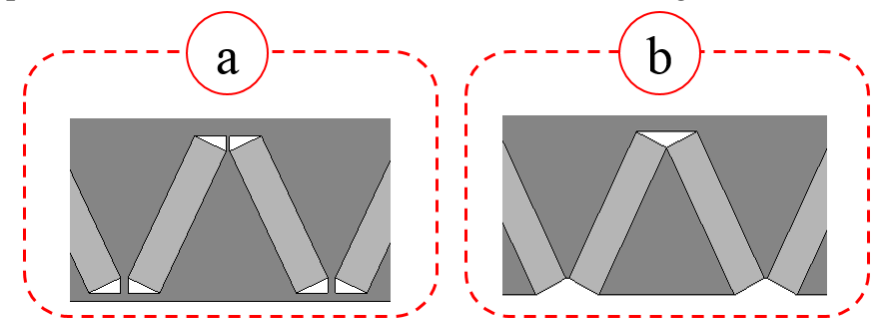

Fig.4. V-shape structure (a) with ribs (b) without ribs.

The pole pitch of this machine is kept equal to that of the baseline machine and each pole consists of a pair of PMs. Each 
stator tooth hosts six poles, as illustrated in Fig. 5.

Airgap flux density is increased by focusing the flux through the triangular pole piece and pole to pole leakage of the baseline design presented in Fig. 6 (a) is shown to be reduced in Fig. 6 (b). In many V shape configurations, especially internal rotor rotary machines, iron ribs are required to secure the pole piece. It is here proposed to use glue instead of iron ribs, Fig. 4(b), to curtail leakage flux. It has been investigated for external rotor rotary machines where a $13 \%$ increase in output torque has been reported [31] by removal of the iron ribs.

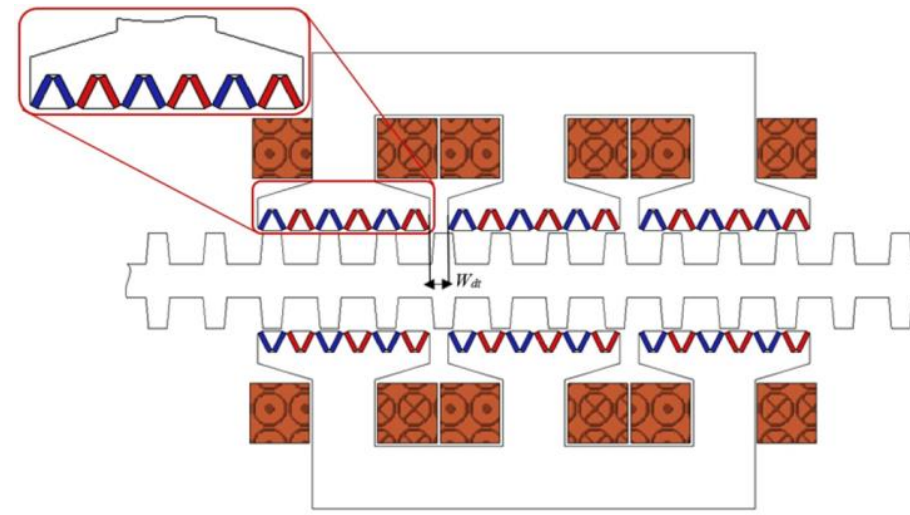

Fig.5. V-shape topology.
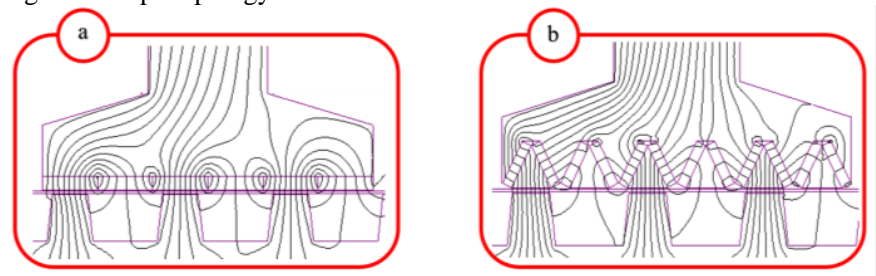

Fig.6. Pole to pole leakage flux (a) baseline and (b) V-shape

In this study, the pole geometry has been constrained by fixing the pole pitch and magnet volume. By varying the value of $\alpha$, defined in Fig.7 as the angle between magnets, the thickness of the magnet is altered to keep the magnet mass constant. $\alpha$ is limited by the minimum permissible magnet thickness, here assumed to be $2 \mathrm{~mm}$.

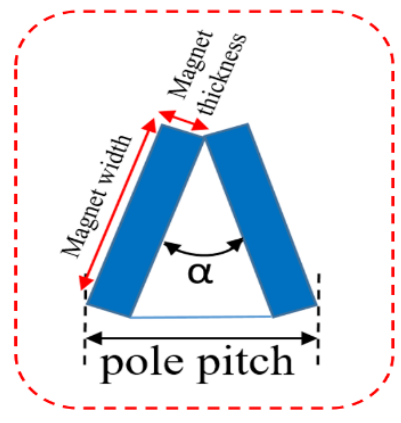

Fig.7. Pole geometry of V shape machine

The effect of varying $\alpha$ on the machine performance has been investigated as shown in Fig. 8 and the results of Table III. Within the stated constraints of this study, clearly the smaller the V-angle, the higher the thrust force which can be achieved. Although the same magnet mass was used in all other designs, however, the pole region becomes smaller and saturated especially in design 4. Design 1, with the smallest angle, thinnest magnet permitted and highest average force, also exhibits the highest cogging force - equating to $5.8 \%$ of the average thrust force. Removal of the iron ribs in this machine was seen to cause a noticeable increase of the $5^{\text {th }}$ and $7^{\text {th }}$ harmonics of the no-load back EMF which can influence the cogging force.

\begin{tabular}{l|cccc}
\multicolumn{5}{c}{ TABLE III: DESIGN STUDY OF MAGNET ANGLE ON V SHAPE PERFORMANCE } \\
\hline \hline Design number & 1 & 2 & 3 & 4 \\
PM width (mm) & 9 & 7.5 & 6 & 5 \\
PM thickness (mm) & 2 & 2.4 & 3 & 3.6 \\
Thrust force (N) & 1802 & 1709 & 1484 & 1274 \\
Cogging force (N) & 106 & 177 & 182 & 125.7 \\
$\alpha$ (degree) & 55.4 & 63.2 & 70.2 & 77.4 \\
\hline \hline
\end{tabular}

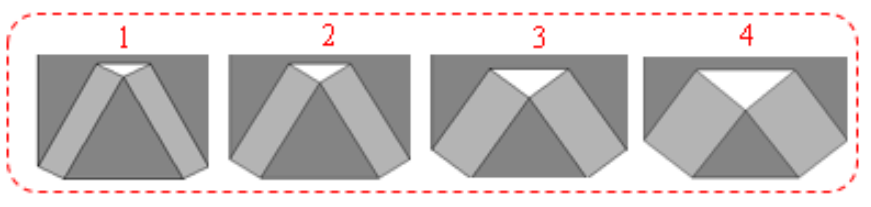

Fig.8. Fixed magnet study of $\mathrm{V}$ shape machine.

\section{Consequent Pole Halbach (CPH)}

Halbach arrays are generally known to reduce leakage flux and so in this topology, consequent poles and Halbach PM arrays are integrated in an attempt to reduce the leakage flux further. For machines with a thicker magnet, Halbach machines have been shown to achieve higher no-load back EMF[32].

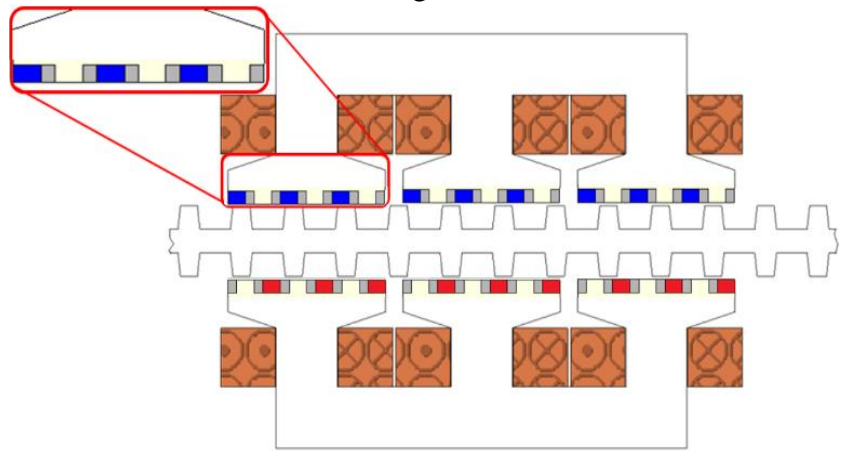

Fig.9. Configuration of consequent Pole Halbach (CPH) machine
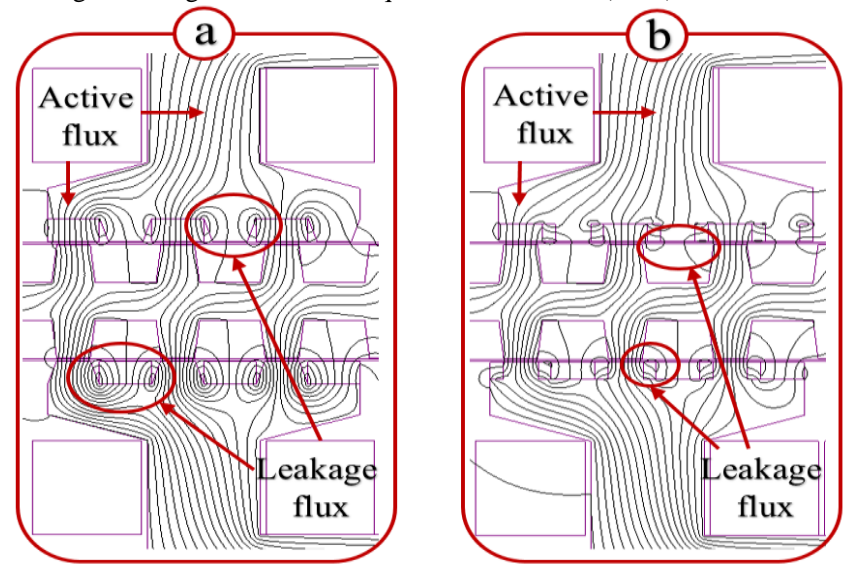

Fig.10. the effect of using Halbach on the leakage flux (a) consequent pole machine (b) consequent pole Halbach machine.

Each set of PM Halbach array consists of three segments of PMs where a vertical magnetized PM (pole magnet) is sandwiched between two horizontal PMs (transition magnets), which are magnetically oriented towards the consequent poles as shown in Fig. 9. The transition magnets also allow the flux 
to be concentrated in the iron poles which can benefit the thrust force density. As shown in Fig.10, the vertically magnetized PMs produce the main flux, while the transition PMs reduce the leakage flux around the edges of PMs leading to a significant improvement of the airgap flux density and hence the power factor [29, 33]. The orientation of the transition magnets used in this study are orientated towards the consequent pole, rather than towards the magnets as presented by other authors [11].

In Halbach machines the thickness of PM has a significant impact on the machine performance including the force production and its ripple. On the other hand, the length of the equivalent airgap can be affected by the magnet thickness which may influence the power factor [8]. All of these factors were considered in the machine design study. The main objective of optimizing the PM thickness is to obtain the maximum achievable thrust force while keeping the power factor at an acceptable value. A further increase of the PM thickness would result in magnetic saturation in the iron poles which may degrade the effectiveness of the magnet utilization.

Since this topology is a combination of consequent poles and Halbach PM arrays, the width of the iron poles is kept the same as that used in CP topology as shown in Fig.11. The rectangular iron poles are used rather than tapered iron poles to allow more space to accommodate the Halbach arrays. Therefore, in order to match the magnet volume of the previous topologies, the thickness of the Halbach array should be $4.5 \mathrm{~mm}$ and the total width is restricted by the consequent poles to $16 \mathrm{~mm}$. The effect of the variation of the ratio of pole magnet to transition magnet on the force is investigated in Table IV. In terms of force, there is an optimum size of pole magnet width: above this value, leakage occurs; below this value there is a reduction in field strength. Based on these results, the width of both pole and transition PMs was chosen to be $10 \mathrm{~mm}$ and $3 \mathrm{~mm}$ respectively, while the thickness of both magnets is kept fixed at $4.5 \mathrm{~mm}$.

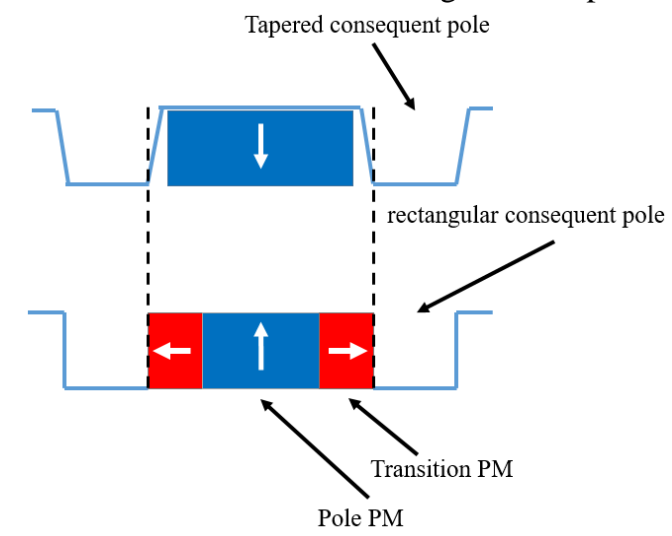

Fig.11. Magnet area for Halbach array.

TABLE IV: DESIGN STUDY ON RATIO OF TRANSITION TO POLE MAGNET

\begin{tabular}{l|ccccc}
\hline $\begin{array}{l}\text { Transition PM width } \\
(\mathrm{mm})\end{array}$ & 1 & 2 & 3 & 4 & 5 \\
Pole PM width (mm) & 14 & 12 & 10 & 8 & 6 \\
Force (N) & 1486 & 1541 & 1566 & 1431 & 1311 \\
Cogging force (N) & 110 & 91 & 57 & 62 & 58 \\
\hline \hline
\end{tabular}

\section{TOPOLOGY PERFORMANCE COMPARISON}

\section{A. Rated Force Capability}

TABLE V. DIMENSIONS OF PMS FOR ALL FOUR MACHINES

\begin{tabular}{lccccc}
\hline \hline & \multirow{2}{*}{ Baseline } & \multirow{2}{*}{ CP } & \multirow{2}{*}{ V-shape } & \multicolumn{2}{c}{ CPH } \\
& & & & $\mathrm{P}$ & $\mathrm{T}$ \\
\hline PM width $(\mathrm{mm})$ & 12 & 12 & 9 & 10 & 3 \\
PM thickness $(\mathrm{mm})$ & 3 & 6 & 2 & 4.5 & 4.5 \\
\hline \hline
\end{tabular}

TABLE VI. FORCE CAPABILITY WITH FIXED MAGNET MASS

\begin{tabular}{lcccc}
\hline \hline & Baseline & CP & V-shape & CPH \\
\hline Back EMF (V) & 73 & 96 & 124 & 103 \\
Force (N) & 1190 & 1490 & 1800 & 1570 \\
Force ripple (\%) & 23 & 5.6 & 9.7 & 5 \\
Cogging force (N) & 134 & 62 & 106 & 61 \\
Power factor & 0.45 & 0.5 & 0.67 & 0.53 \\
\hline \hline
\end{tabular}

The four topologies have been simulated and compared using FEA to investigate the effect of the PM configuration on thrust force and power factor. For this first comparison all machines have the same overall volume, PM volume, current density and rated speed. The aim of this section is to investigate magnet utilization. The magnet dimensions for all investigated machines are shown in Table $\mathrm{V}$ and the performance is shown in Table VI. The highest no-load back EMF, thrust force and power factor can be achieved by adopting the V-shape structure. This is due to that fact that this machine has the lowest leakage flux and uses flux concentration to enhance airgap flux density. In addition, although the peak to peak cogging force produced by this machine is higher than that of $\mathrm{CP}$ and $\mathrm{CPH}$ machines, this value represents only $5.6 \%$ with respect to the average thrust force and it is $26 \%$ less than that produced by the baseline machine.

The use of consequent pole can significantly reduce the leakage flux and improve the main flux meaning that this machine can produce $24.7 \%$ higher thrust force than that of the baseline design. Moreover, the CP structure exhibits low cogging force due to the lower interaction between PMs and translator teeth offering smooth operation at low speed. The power factor of this machine is improved by $24 \%$, and that is due to the implementation of the tapered ferromagnetic poles which further influences the leakage flux [8, 32].

The CPH machine reduces the pole to pole leakage flux and hence increases the main flux and no-load back EMF. This machine is capable of generating $32 \%$ and $5 \%$ higher thrust force compared with that produced by the baseline and $\mathrm{CP}$ machines, whilst it offers the minimum cogging force among all the four machines. Increased back emf improves the power factor of the $\mathrm{CPH}$ by $10 \%$ compared with the conventional $\mathrm{CP}$. 


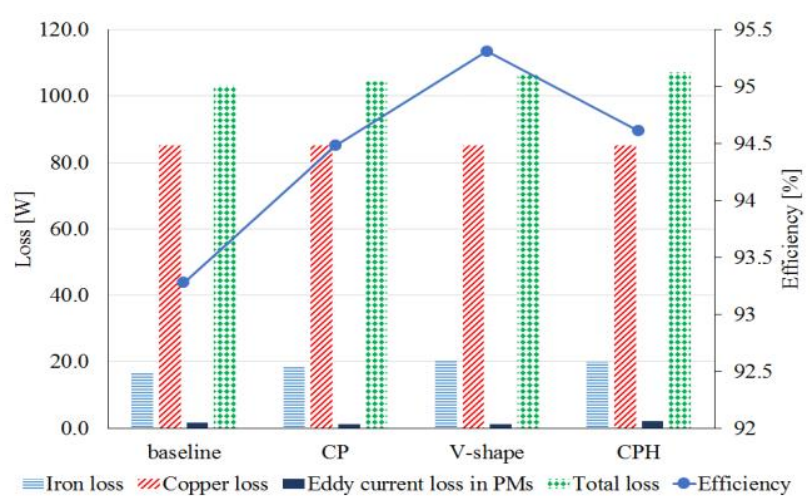

Fig.12. Machine efficiency of all topologies at fixed current density.

In order to evaluate the efficiency of all four machines at the same rated speed, the losses including copper losses, iron losses and eddy current in PMs were predicted using transient simulations. The iron losses and eddy current losses in PMs were calculated by the FEA whereas the copper losses were manually calculated.

Fig.12 illustrates the losses and efficiency for the four investigated machines. It can be seen that due to the increase in the maximum value of the magnetic flux density $\left(B_{\max }\right)$ in the $\mathrm{V}$-shape and CPH designs the iron loss is slightly higher than the other two designs. However, the highest efficiency can be achieved by the V-shape machine as it produces the highest output power, whereas the baseline design exhibits the minimum efficiency.

This first study hence shows that the V shape machine can deliver the highest output thrust at the highest efficiency and power factor of all the machines studied in this fixed magnet mass fixed current density scenario. These machines are all delivering different average forces and hence differing amounts of electrical power, so cannot be compared for a specific design requirement.

\section{B. Efficiency and power factor for fixed power}

In this section, the $\mathrm{CP}, \mathrm{V}$-shape and $\mathrm{CPH}$ machines are designed to match the force produced by the baseline by reducing the current density. The purpose of this investigation is to evaluate the operating efficiency of the topologies which have the same mechanical power (force $x$ velocity), the same volume of magnet material and hence nominally same capital cost. All three designs require a reduced current density compared to the base-line. Under these assumptions, as stated in (3), the power factor and efficiency provide good criteria to asses these machines.

The efficiency and power factor results are summarized in Fig. 13 and are produced by reducing the current by $36.9 \%$, $36.9 \%$ and $27.7 \%$ respectively for the $\mathrm{CP}, \mathrm{V}$-shape and $\mathrm{CPH}$ machines.
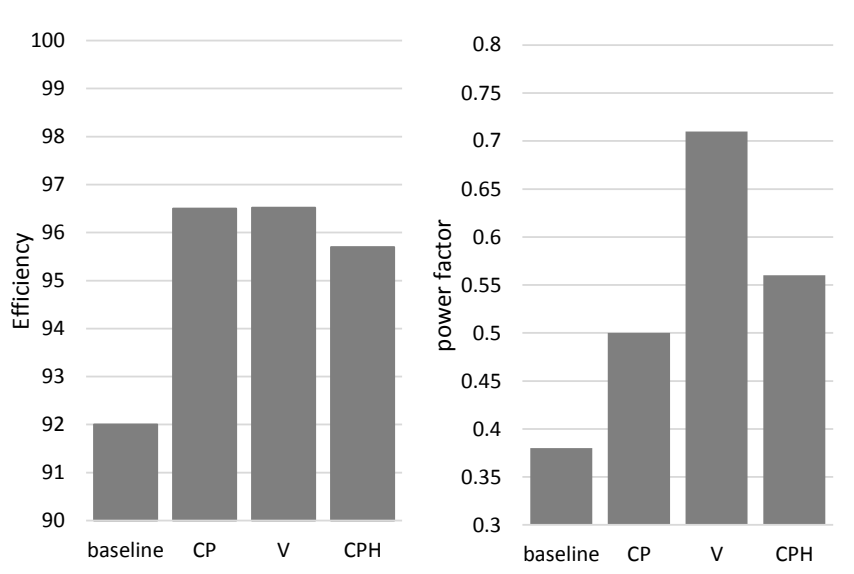

Fig.13. Efficiency and power factor for all machines with a constant mechanical power achieved by varying current density.

The results of this second study show the $\mathrm{V}$ shape machine offers the best power factor and efficiency for fixed magnet mass and fixed rated output power.

\section{Power factor improvement}

Equation (2) highlighted that power factor was one of the 3 main parameters affecting cost of energy. Low power factors are inherent in this type of machine although Section III A-B revealed that minor topology changes can make a significant improvement for a fixed output force. In literature, different topologies have been proposed to improve the PF. One such method, involving an auxiliary DC winding was employed in [34] which naturally leads to an increase in copper loss, converter loss and material cost. In addition, its PMs are located on the translator resulting in poor magnet utilization for linear machines with a large amplitude of oscillation. In [26], the authors proposed an effective topology of a rotary Vernier machine with an improved power factor. Again, converting this machine into linear version requires a large amount of PM material since the PMs are located in the translator.

Alternatively, increasing the axial length of any of these machines allows the electrical load to be reduced whilst maintaining the output force. Referring to (4), $I$ will decrease and $\Psi_{m}$ will increase, so an increase in axial length can hence be used as a way of improving power factor but at the expense of magnet mass. All four topologies are scaled in the axial direction from $50 \mathrm{~mm}$ to $80 \mathrm{~mm}$ to look at the effect on power factor. As before, the current density is reduced to maintain a constant output force.

For all topologies, the power factor is shown in Fig. 14 to increase almost linearly with an increase in axial length. For example, the V-shape machine could operate with a power factor of 0.93 for a $60 \%$ increase in magnet mass. To match the power factor of the $\mathrm{CP}$ machine, the baseline machine would require an increase of approximately $40 \%$ of magnet mass. 


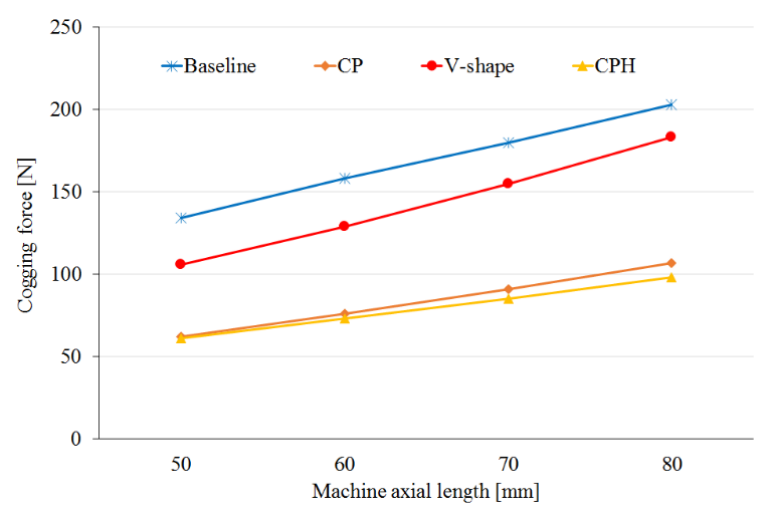

Fig.14. Variation of the power factor with respect to the machine axial length

The no-load back EMF and cogging force of each machine will also increase with axial length. Although the V-shape design offers the power factor of 0.93 at the axial length of 80 $\mathrm{mm}$, its cogging force is about $12.4 \%$ of the average force. This is due to the increase in THD of the no-load back EMF. However, this can be reduced by skewing [35], or asymmetrical poles configuration [36]. It can be also observed that the worst cogging force is produced by the baseline design, while the minimum cogging force is achieved by $\mathrm{CP}$ and $\mathrm{CPH}$ respectively.

Within the constraints of this study, the $\mathrm{V}$ shape machine can offer the best power factor per unit magnet mass of all the topologies studied. To match the power factor of the $\mathrm{V}$ shape machine, the baseline machine would require almost twice the magnet mass. Very high power factors are achievable by all topologies if axial length, and hence magnet mass, were not a constraint. The relative values of $A$ and $B$ in (2) would be required to fully resolve this design problem.

\section{Validation}

To validate these results, the $\mathrm{CP}, \mathrm{V}$ and $\mathrm{CPH}$ machines have been prototyped as shown in Fig 15.

The machines are driven by a ball screw with a $100 \mathrm{~mm}$ stroke length, able to offer a region of near constant velocity over two of electrical cycles. To ease mechanical forces on the rig, and in particular on the magnet retaining glue, the airgap for the test machine was initially set to $2 \mathrm{~mm}$, whereas in the comparison it was assumed to be $1 \mathrm{~mm}$. This has the effect of reducing the machine performance, but improving the harmonic performance. The open circuit emf waveforms of Fig. 16 are near sinusoidal, with a $3 \%$ discrepancy on the RMS value between measured and predicted values.

Fig 17 shows the cogging force, measured at 0 Amps and near constant speed of $0.02 \mathrm{~m} / \mathrm{s}$. The amplitude for the measured force is similar to simulations, although the peaks of the ripples do not always line up. Looking at the RMS force over a whole number of electrical cycles, there is a $13 \%$ error. The force being measured are close to the resolution of the equipment, and is also comparable to friction within the linear slides. A description of the test-rig and a discussion of validation of finite element models for similar linear machines is given in [37]. For validation purposes, these results give adequate confidence in machine simulated results.

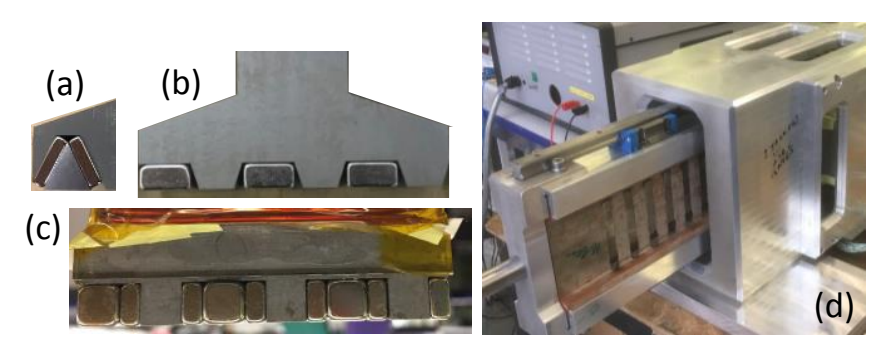

Fig.15. Prototypes (a) V shape stator (b) $\mathrm{CP}$ stator (c) $\mathrm{CPH}$ stator (d) $\mathrm{CPH}$ translator inserted into stator.

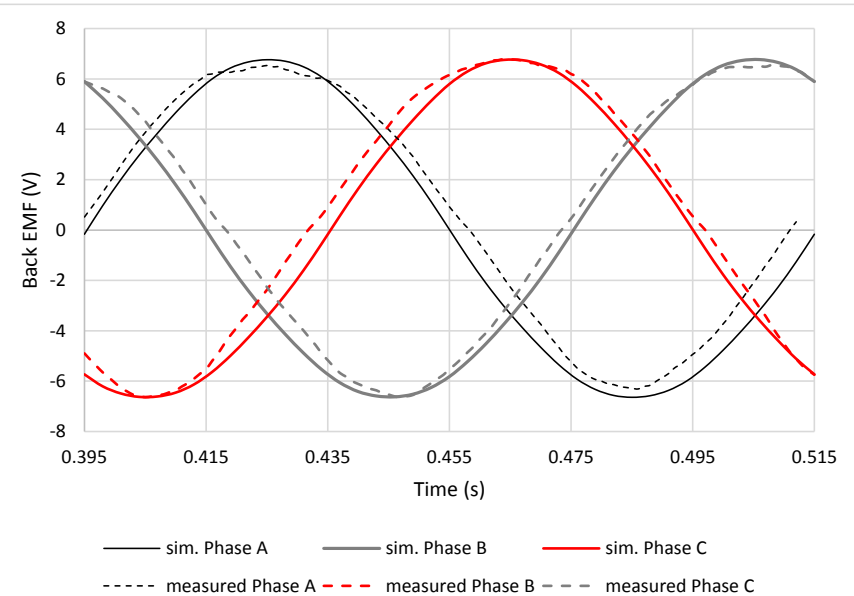

Fig.16. Open circuit emf at $0.2 \mathrm{~m} / \mathrm{s}$ for the $\mathrm{CPH}$ with airgap set at $2 \mathrm{~mm}$.

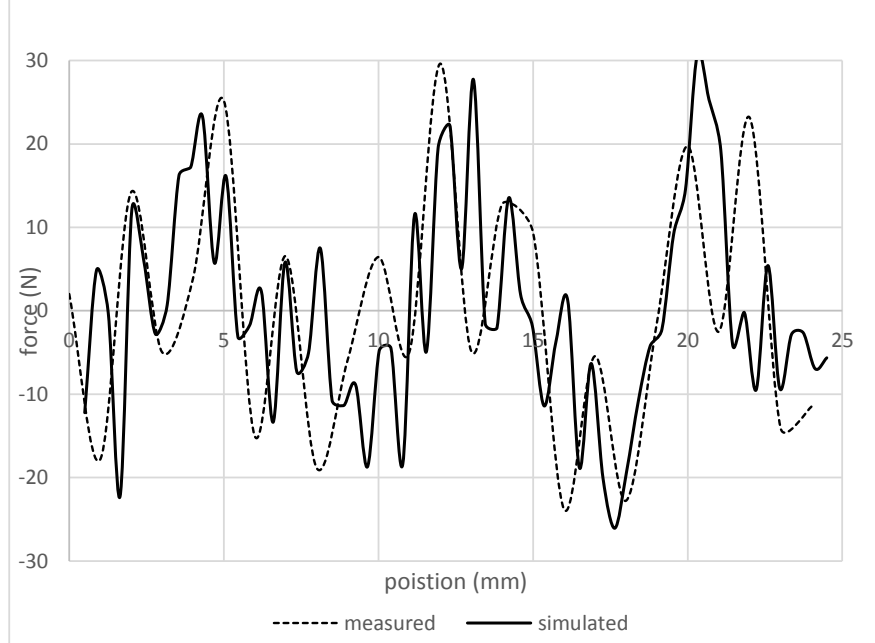

Fig.17. Open circuit emf at $0.2 \mathrm{~m} / \mathrm{s}$ for the $\mathrm{CPH}$ with airgap set at $2 \mathrm{~mm}$.

\section{MECHANICAL INTEGRATION}

The challenges and opportunities of a more integrated generator design within a wave device were highlighted in Section 1. Fully flooded operation is proposed as providing the optimum integrated design. The impact of flooded operation on the design of the critical components, the bearings and the windings, is discussed in this section.

\section{A. Bearing Design}

With a linear machine in a flooded environment, the use of ball bearing technology is not an option. Polymeric bearing materials have been used as journal bearings in ship propulsion 
systems, and have been tested for linear applications. Standard bearing testing involves the application of point loads, but this is not representative of loading within a linear machine, in which the bearing loads will be more distributed. A bearing test rig was custom made with bearing pads arranged in such a way that would represent use within a linear generator. As shown in Fig. 18, three pads are mounted on a bearing holder, which would then run along a guide rail.
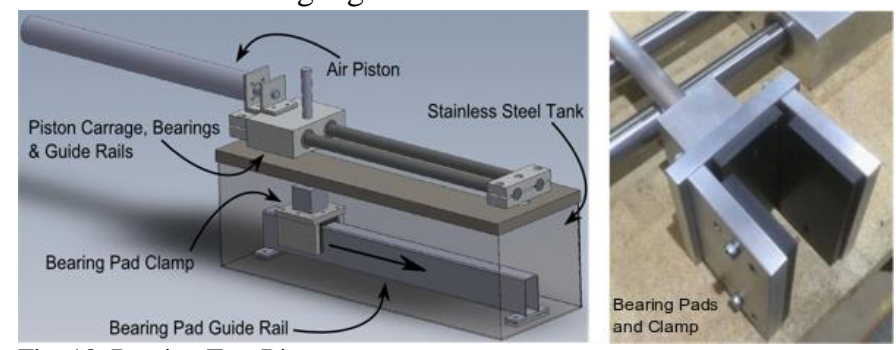

Fig. 18. Bearing Test Rig.
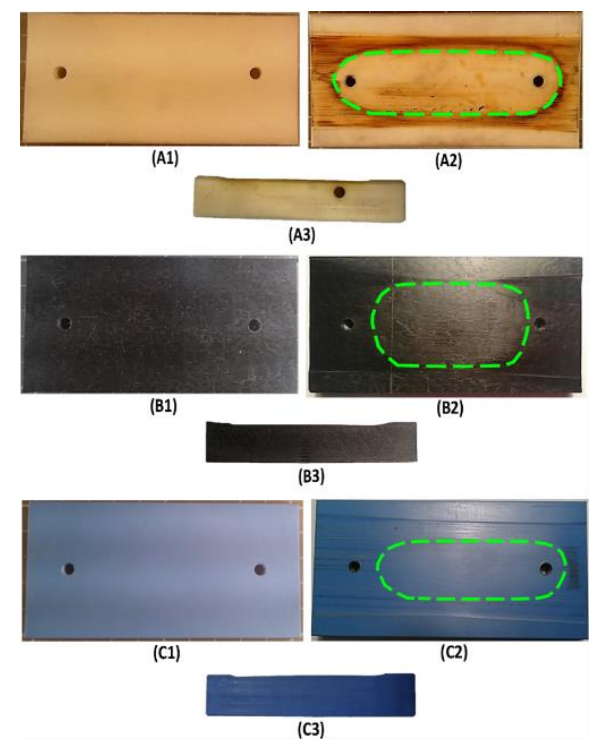

Fig. 19. Samples of 3 different polymer bearings with highlighted areas showing wear.

The test rig is powered using a compressed air pneumatic ram which moves the bearing material back and forth along a stainless steel guide rail. Compressed air actuators apply vertical and torsional loads to the bearing pads during testing, to emulate additional loads due to wave loading for example. The tank can be used to operate the bearings dry or flooded.

Each bearing material was tested under constant vertical and tangential loads for a continuous period of 170 hours at a speed of up to $0.75 \mathrm{~m} / \mathrm{s}$ with a stroke length of $0.5 \mathrm{~m}$, replicating a distance of $500 \mathrm{~km}$ and 500000 cycles, which equates to 6 months of real time operation. The "clean" salt water environment tests will follow using artificial sea water with salinity of 35 parts per thousand, mimicking average ocean and sea marine environments. Fig. 19 shows an example of physical bearing wear and Fig. 20 shows the resultant mass reduction of one sample.

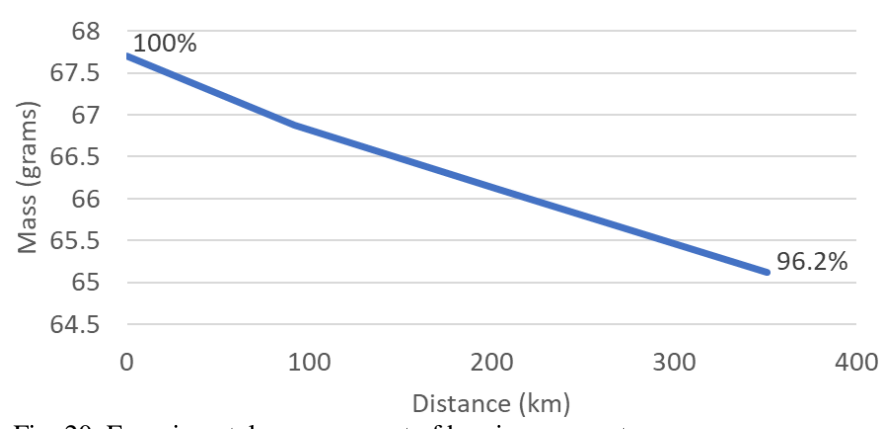

Fig. 20. Experimental measurement of bearing wear rate

With such results it is possible to estimate wear rates accurately for certain loadings, and thus to plan operation and maintenance operations. The wear has been extrapolated to the equivalent of 5 years operation, where a 5-year operation and maintenance period is thought to be acceptable for marine applications.

\section{B. Thermal Performance of Coils}
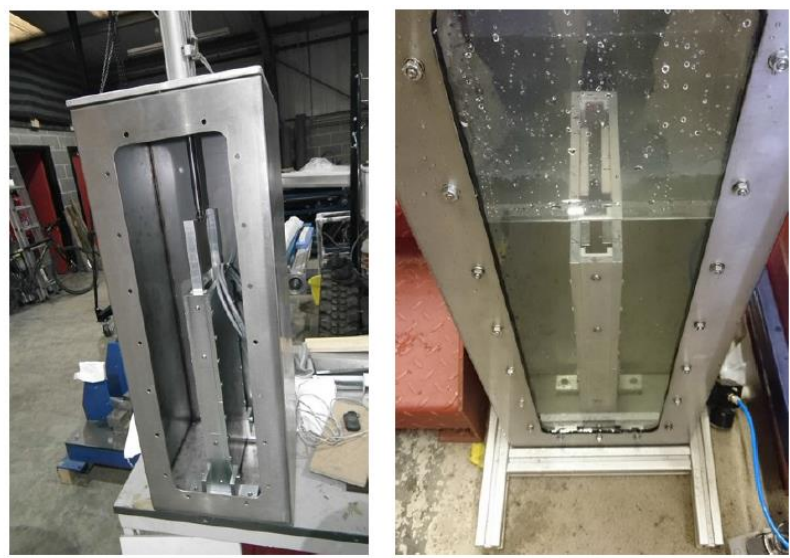

Fig. 21. Small test tank for flooded testing of coils

Concentrated coils mounted on iron poles are used in all variants of the VHM machine studied here. In order to protect the copper from the marine environment, it is proposed to cover these coils with epoxy resin. In order to investigate the thermal performance of epoxy coated coils in water, concentrated aircored coils were tested in a small tank with motion. Fig. 21 shows the tank used and Fig. 22 shows the topology of the coils. There were three coils in each coil sample. Two samples were epoxy coated (blue color) and a third non-epoxy coated sample was built for comparison.

Each sample was tested initially stationary to allow the temperature to stabilize, and then the coils were moved in a linear manner, with the displacement as close to sinusoidal as possible. Fig. 23 shows the resulting temperature profile for the three different samples. Whilst stationary the temperature rises to $50^{\circ} \mathrm{C}$ for the one of the epoxy coated coils, and to $40^{\circ} \mathrm{C}$ for the enameled coils and the other epoxy coated coils. As soon as the motion begins the temperature drops, with the minimum equal to $20^{\circ} \mathrm{C}$. The epoxy coated coils perform just as well as the enameled coils, and so the thermal conductivity of the epoxy is not a limiting factor providing confidence that epoxy coatings can be used for protection without any major impact on thermal performance. Although air-cored coils are used in the tests, it is 
anticipated that a similar result will occur for the concentrated coils used in the VHM.

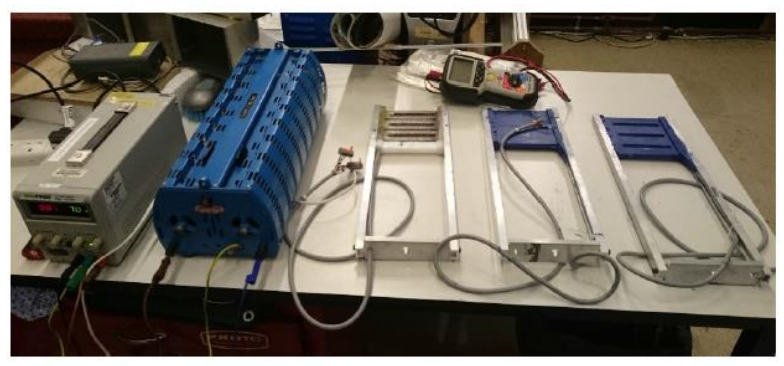

Fig. 22. Three different concentrated coil samples

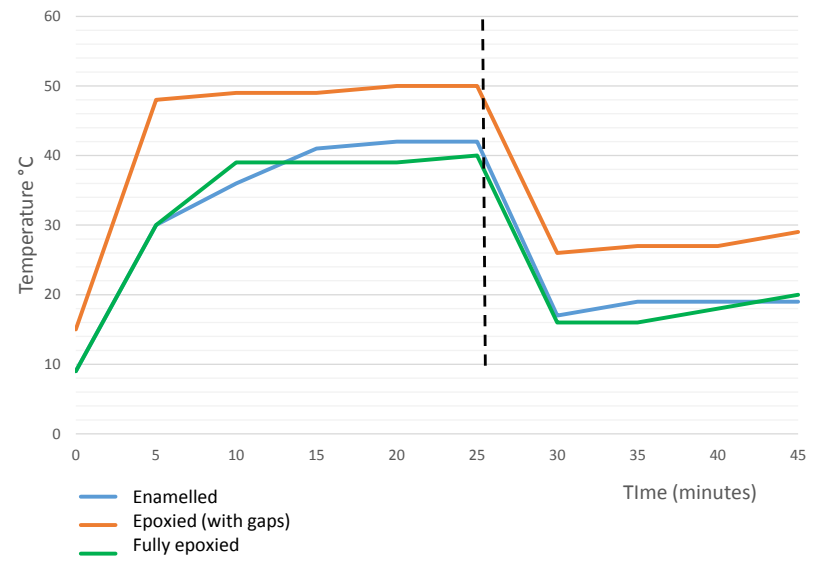

Fig. 23 Thermal performance, external coil temperature with $8 \mathrm{~A} /$ coil Movement of translator initiated at $0.25 \mathrm{~m} / \mathrm{s}$ for enameled coils, $0.35 \mathrm{~m} / \mathrm{s}$ for epoxied coils with gaps and $0.25 \mathrm{~m} / \mathrm{s}$ for fully epoxied.

With natural air cooled machines a current density of 4 $\mathrm{A} / \mathrm{mm}^{2}$ is typical, but results from the mini test rig suggest that more than $18 \mathrm{~A} / \mathrm{mm}^{2}$ could be achieved (wire diameter is 0.75 $\mathrm{mm}$, at a current of $8 \mathrm{~A}$ ). As a result of this improved cooling the power density could be increased by about a factor of 5 , which will reduce material costs per $\mathrm{kg}$, but at the expense of efficiency. As for the preceding sections, the relative values of $A$ and $B$ in (2) would be required to fully resolve this design problem. More importantly for wave energy applications, the flooded linear generator would be able to survive extreme overload conditions without concern over temperature rise.

\section{Integration into the Wave Device}

A fully flooded device provides for a more versatile design enabling a greater degree of integration between the generator and the actual wave device. As stated earlier the generator tends to be in a sealed environment, perhaps mounted on the sea-bed and then mechanically coupled to a heaving buoy via chains or similar. Access to the generator is limited, and the use of chains and additional bearing systems add to OPEX.

Fig. 24 shows how a flooded generator can now be integrated into the device. The yellow sections represent the heaving buoy device, and the moving parts of the linear generator are integrated into the buoy structure. A single polymer bearing system provides the interface between stationary and moving parts. The stationary windings are held supported on a buoyant drag plate.

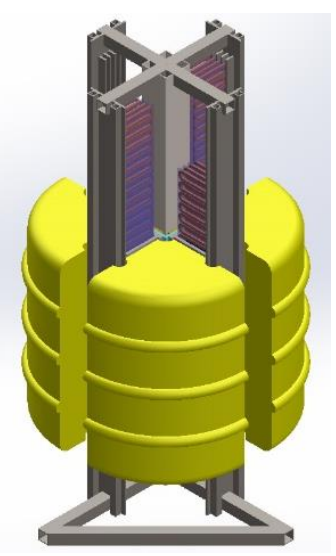

Fig. 24. Fully integrated linear generator heaving buoy

\section{CONCLUSION}

The authors have presented aspects of both electrical and mechanical design of four linear VHM generator topologies. The topology variants were studied with due consideration to their effect on the cost of energy produced by a $25 \mathrm{~kW}$ wave energy device. It was argued that power factor and efficiency were the two most important aspects for this application. For a fixed magnet mass and fixed output power, a V shape topology was shown to give the best performance, with a machine efficiency of over $96 \%$ and a power factor greater than 0.7 . The analysis was based on finite element analysis validated by back emf and no load force profiles measured in the laboratory.

In terms of physical integration, the modular nature of the linear VHM and flooded operation makes the overall mechanical design and integration into a wave device more versatile. The proposed polymer bearing system lends itself to linear generators with a high degree of modularity inherent in the linear VHM and can offer a 5 year lifetime. The use of epoxy materials provides protection for critical components such as the coils and magnets, but with little impact on thermal performance. In fact flooded operation provides potential in terms of survivability of extreme conditions, in which the generator may be used to shed load under high current densities.

\section{REFERENCES}

J. Faiz and A. Nematsaberi, "Linear electrical generator topologies for direct-drive marine wave energy conversion-an overview," IET Renewable Power Generation, vol. 11, no. 9, pp. 1163-1176, 2017. L. Huang, M. Hu, Z. Chen, H. Yu, and C. Liu, "Research on a directdrive wave energy converter using an outer-pm linear tubular generator," IEEE Trans. on Magn., vol. 53, no. 6, pp. 1-4, 2017.

[3] A. Wahyudie, M. Jama, T. B. Susilo, B. F. Mon, H. Shaaref, and H. Noura, "Design and testing of a laboratory scale test rig for wave energy converters using a double-sided permanent magnet linear generator," IET Renewable Power Generation, vol. 11, no. 7, pp. 922-930, 2017.

[4] O. Farrok, M. R. Islam, M. R. I. Sheikh, Y. Guo, and J. G. Zhu, "Design and analysis of a novel lightweight translator permanent magnet linear generator for oceanic wave energy conversion," IEEE Trans. on Magn., vol. 53, no. 11, pp. 1-4, 2017.

[5] H. Polinder, B. C. Mecrow, A. G. Jack, P. G. Dickinson, and M. A. Mueller, "Conventional and TFPM linear generators for direct-drive wave energy conversion," IEEE Trans. Energy Convers., vol. 20, no. 2, pp. 260-267, 2005.

[6] H. Jing, N. Maki, T. Ida, and M. Izumi, "Study on Key Design Technologies of a Wave Energy Converter With an HTS Linear 
Generator," IEEE Trans. Appl. Supercond., vol. 27, no. 7, pp. 1-8, 2017.

[7] M. A. Mueller and N. J. Baker, "Modelling the performance of the vernier hybrid machine," IEE Proc. Elect. Power Appl., vol. 150, no. 6 , pp. $647-654,2003$

[8] A. A. Almoraya, N. J. Baker, K. J. Smith, and M. A. H. Raihan, "Development of a double-sided consequent pole linear vernier hybrid permanent-magnet machine for wave energy converters," in IEEE Int. Electric Machines and Drives Conf. (IEMDC) 2017, pp. $1-7$.

[9] M. A. H. Raihan, N. J. Baker, K. J. Smith, and A. A. Almoraya, "Investigation of a doubly salient Halbach array linear permanent magnet machine for wave energy converters," in Electrical Machines and Systems (ICEMS), 2017 20th International Conference on, 2017, pp. 1-5: IEEE.

[10] Y. Du, M. Cheng, K. T. Chau, X. Liu, F. Xiao, and W. Zhao, "Linear primary permanent magnet vernier machine for wave energy conversion," IET Elect. Power Appl., vol. 9, no. 3, pp. 203-212, 2015.

[11] J. Ji, W. Zhao, Z. Fang, J. Zhao, and J. Zhu, "A novel linear permanent-magnet vernier machine with improved force performance," IEEE Trans. on Magn., vol. 51, no. 8, pp. 1-10, 2015.

[12] A. Nematsaberi and J. Faiz, "A Novel Linear Stator-PM Vernier Machine With Spoke-Type Magnets," IEEE Trans. on Magn., no. 99, pp. 1-5, 2018.

[13] C. Shi, R. Qu, Y. Gao, D. Li, L. Jing, and Y. Zhou, "Design and Analysis of an Interior Permanent Magnet Linear Vernier Machine," IEEE Trans. on Magn., no. 99, 2018.

[14] Y. Shen and Q. Lu, "Design and Analysis of Linear Hybrid-Excited Slot Permanent Magnet Machines," IEEE Trans. on Magn., no. 99, 2018.

[15] W. Zhao, J. Zheng, J. Wang, G. Liu, J. Zhao, and Z. Fang, "Design and analysis of a linear permanent-magnet vernier machine with improved force density," IEEE Trans. on Ind. Electron, vol. 63, no. 4, pp. 2072-2082, 2016.

[16] G. Liu, L. Ding, W. Zhao, Q. Chen, and S. Jiang, "Nonlinear Equivalent Magnetic Network of a Linear Permanent Magnet Vernier Machine With End Effect Consideration," IEEE Trans. Magn., vol. 54, no. 1, pp. 1-9, 2018.

[17] H. Zhang, B. Kou, Z. Zhu, R. Qu, J. Luo, and Y. Shao, "Thrust Ripple Analysis on Toroidal-Winding Linear Permanent Magnet Vernier Machine," IEEE Trans. on Ind. Electron., 2018.

[18] C. Shi, D. Li, R. Qu, H. Zhang, Y. Gao, and Y. Huo, "A novel linear permanent magnet vernier machine with consequent-pole permanent magnets and Halbach permanent magnet arrays," IEEE Trans. on Magn., vol. 53, no. 11, pp. 1-4, 2017.

[19] P. Tavner, Offshore wind turbines: Reliability Availability and Maintenance, . London, UK: The Institution of Engineering and Technology, 2012.

[20] R. Waters et al., "Experimental results from sea trials of an offshore wave energy system," Appl. Physics Lett., vol. 90, no. 3, p. 034105, 2007.

[21] M. G. de Sousa Prado, F. Gardner, M. Damen, and H. Polinder, "Modelling and test results of the Archimedes wave swing," Proceedings of the Institution of Mechanical Engineers, Part A: Journal of Power and Energy, vol. 220, no. 8, pp. 855-868, 2006.

[22] D. Elwood et al., "Design, construction, and ocean testing of a tautmoored dual-body wave energy converter with a linear generator power take-off," Renewable Energy, vol. 35, no. 2, pp. 348-354, 2010.

[23] J. Callaghan and R. Boud, "Future Marine Energy. Results of the Marine Energy Challenge: Cost competitiveness and growth of wave and tidal stream energy," in "Carbon Trust," 2006.

[24] P. Tokat and T. Thiringer, "Sizing of IPM Generator for a Single Point Absorber Type Wave Energy Converter," IEEE Trans. on Energy Convers., vol. 33, no. 1, pp. 10-19, 2018.

[25] N. Baloch, S. Khaliq, and B.-I. Kwon, "A high force density HTS tubular Vernier machine," IEEE Trans. Magn., vol. 53, no. 11, pp. $1-5,2017$.

[26] D. Li, R. Qu, and T. A. Lipo, "High-power-factor vernier permanent-magnet machines," IEEE Trans. Ind. Appl., vol. 50, no. 6, pp. 3664-3674, 2014.

[27] M. A. H. Raihan, N. J. Baker, K. J. Smith, and A. A. Almoraya, "An E-core linear veriner hybrid permanent magnet machine with segmented translator for direct drive wave energy converter," in
IEEE Int. Electric Machines and Drives Conf. (IEMDC) 2017, pp. 1-6: IEEE.

[28] S.-U. Chung, J.-W. Kim, B.-C. Woo, D.-K. Hong, J.-Y. Lee, and D.H. Koo, "A novel design of modular three-phase permanent magnet vernier machine with consequent pole rotor," IEEE Trans. on Magn., vol. 47, no. 10, pp. 4215-4218, 2011.

[29] Y. Huo, R. Qu, Y. Gao, S. Jia, and X. Fan, "Design of a linear vernier permanent magnet machine with high thrust force density and low thrust force ripple," in IEEE Int. Electric Machines and Drives Conf. (IEMDC) 2017, pp. 1-6: IEEE.

[30] S. Yang et al., "Cost reduction of a permanent magnet in-wheel electric vehicle traction motor," in Int. Conf. on Electrical Machines (ICEM), 2014, pp. 443-449: IEEE.

[31] S. Yang, I. Kakavas, N. J. Baker, B. C. Mecrow, C. Hilton, and D. K. Perovic, "The assembly of a V shape in-wheel motor with reduced mechanical support," 2016.

[32] A. Almoraya, N. Baker, K. Smith, and M. Raihan, "An investigation of a linear flux switching machine with tapered ferromagnetic poles," in Electrical Machines and Systems (ICEMS), 2017 20th International Conference on, 2017, pp. 1-5: IEEE.

[33] K. Xie, D. Li, R. Qu, Y. Gao, and Y. Pan, "A novel flux reversal PM Machine with Halbach array magnets in stator slot opening," in Electrical Machines and Systems (ICEMS), 2017 20th International Conference on, 2017, pp. 1-6: IEEE.

[34] T. Ching, K. Chau, and W. Li, "Power factor improvement of a linear vernier permanent-magnet machine using auxiliary DC field excitation," IEEE Trans. Magn., vol. 52, no. 7, pp. 1-4, 2016.

[35] S.-U. Chung, J.-W. Kim, B.-C. Woo, D.-K. Hong, J.-Y. Lee, and D.$\mathrm{H}$. Koo, "Force ripple and magnetic unbalance reduction design for doubly salient permanent magnet linear synchronous motor," IEEE Trans. on Magn., vol. 47, no. 10, pp. 4207-4210, 2011.

[36] W. Ren, Q. Xu, and Q. Li, "Asymmetrical V-shape rotor configuration of an interior permanent magnet machine for improving torque characteristics," IEEE Trans. on Magn., vol. 51, no. 11, pp. 1-4, 2015.

[37] N. J. Baker, A. S. Jalal, J. Wang, and R. M. Korbekandi, "A study of the assembly, build and test of a linear transverse flux machine," 9th IET Int. Conf. on Power Electronics, Machines and Drives (PEMD 2018). 